University of Nebraska - Lincoln

DigitalCommons@University of Nebraska - Lincoln

USDA National Wildlife Research Center - Staff Publications
U.S. Department of Agriculture: Animal and Plant Health Inspection Service

2018

\title{
Consistent individual behavior: evidence of personality in black bears
}

Patrick J. Myers

Utah State University

Julie K. Young

USDA National Wildlife Research Center, julie.k.young@aphis.usda.gov

Follow this and additional works at: https://digitalcommons.unl.edu/icwdm_usdanwrc

Part of the Life Sciences Commons

Myers, Patrick J. and Young, Julie K., "Consistent individual behavior: evidence of personality in black bears" (2018). USDA National Wildlife Research Center - Staff Publications. 2126.

https://digitalcommons.unl.edu/icwdm_usdanwrc/2126

This Article is brought to you for free and open access by the U.S. Department of Agriculture: Animal and Plant Health Inspection Service at DigitalCommons@University of Nebraska - Lincoln. It has been accepted for inclusion in USDA National Wildlife Research Center - Staff Publications by an authorized administrator of DigitalCommons@University of Nebraska - Lincoln. 


\title{
Consistent individual behavior: evidence of personality in black bears
}

\author{
Patrick J. Myers ${ }^{1}$ Julie K. Young ${ }^{2}$ \\ Received: 16 November 2017 / Accepted: 18 February 2018 / Published online: 28 February 2018 \\ (c) This is a U.S. Government work and not under copyright protection in the US; foreign copyright protection may apply 2018
}

\begin{abstract}
Personality is defined as consistency in individual differences in organismal behavior across time or context, a phenomenon of interest within behavioral and evolutionary ecology. Empirical data have revealed an ever-increasing number and diversity of taxa that display these phenotypic patterns in both wild and captive settings. Moreover, these behavioral traits are frequently linked to wild behavior, life history strategies, and measures of individual fitness. Understanding personality is of particular importance for some animals, such as large carnivores, which may express maladaptive behavior that can lead to conflict with humans. To date, few studies of personality exist on large carnivores and none have investigated the presence of personality in black bears (Ursus americanus). Through focal animal sampling, and open field, novel object, and startle object tests, we investigate the potential for personality in captive black bear cubs. Results indicate the presence of personality, with consistency in behavior across five metrics for the bold-shy axis, and eight sampling events measuring responses for the activity axis. Information presented here reveals the presence of personality in black bear cubs, and may provide a framework for future investigations into relationships of personality with ecology and life history.
\end{abstract}

Keywords Novel object $\cdot$ Open field $\cdot$ Repeatability $\cdot$ Ursus americanus $\cdot$ Captive $\cdot$ Startle object $\cdot$ Activity

\section{Introduction}

An ever-growing body of empirical data demonstrates that individual animals display consistency in behavior across time or context (Bell et al. 2009; Stamps and Groothuis 2010). Repeatable individual behavior has been recognized for more than a century within the discipline of human psychology (Caspi et al. 2005), but only of late has attention been drawn to this in studies of non-human animal behavior (Gosling 2001; Bell et al. 2009; Réale et al. 2010). Influenced in large part by the seminal work of Wilson et al. (1994), studies of personality in non-human animals (hereafter, "animal personality" or, simply, "personality") frequently include measurements along continua within one of several broad behavioral traits, such as boldness, exploration,

Julie K. Young

julie.young@usu.edu

1 Department of Wildland Resources, Utah State University, 5230 Old Main Hill, Logan, UT 84322-5230, USA

2 USDA National Wildlife Research Center, Predator Research Facility, Department of Wildland Resources, Utah State University, 5230 Old Main Hill, Logan, UT 84322-5230, USA activity, aggression, or sociability. These metrics are often used to define personality or behavioral profiles of individual animals (Réale et al. 2007). Observations of behavioral consistency within individual animals provide an alternative to the long-standing perspective that organisms are phenotypically plastic in response to repeated stimuli (West-Eberhard 1989). Between-individual differences in behavior are now being recognized as indicative of individuality and no longer considered mere deviations from the population mean (Wolf and Weissing 2012). Moreover, many studies have identified that personality traits are not always expressed in isolation, but as suites of correlated behaviors called behavioral syndromes (Sih et al. 2004); for example, an organism may consistently display aggression in one context and boldness in another (Kortet and Hedrick 2007).

Animal personality is now garnering attention regarding its implications for organismal life history and evolution (Wolf and Weissing 2012). For instance, personality traits have been linked to some of the most fundamental of animal behaviors, including reproduction (Cote and Clobert 2007; Réale et al. 2009), foraging (Johnson and Sih 2005), and dispersal (Cote et al. 2010), as well as to some of the most basic life processes, such as metabolism (Careau et al. 2008) and growth rate (Adriaenssens and Johnsson 2010). With 
animal behavior so closely linked to fitness (Dingemanse and Réale 2005), advances in conservation and evolutionary biology necessitate a more thorough understanding of animal personality and behavioral variation, including their ecological and evolutionary implications.

Assessments of animal personality have relied on several principal testing strategies. Open-field trials, which are used to assay a variety of behavioral traits, consist of observations of individuals' behavior in environments to which they are naïve (Valle 1970; Walsh and Cummins 1976; Burns 2008). One such behavior, "wall-hugging," is an anxietyrelated response along the bold-shy axis, in which less bold subjects avoid the interior of unfamiliar or stressful environments. This has been observed in many taxa, including fish (Sharma et al. 2009), rodents (Treit and Fundytus 1988), and humans (Kallai et al. 2007). Exploration is measured as the inclination of animals to investigate novel environments, and has been demonstrated to be correlated with risk-taking and negatively related to neophobia (Meehan and Mench 2002; Mettke-Hofmann et al. 2002; van Oers et al. 2004; Dingemanse et al. 2010; Cole and Quinn 2014). Assays whereby animals are presented with an unfamiliar object which may be interpreted as a threat, are referred to as novel-object tests, and are commonly used to measure fear, with bold subjects less fearful of the object (Burns 2008). Similarly, startle objects, such as light or sound, are used to measure behavior along the bold-shy axis, whereby flight from or latency to return to an object following a stimulus often correspond with levels of boldness (van Oers et al. 2004; Ward et al. 2007). Finally, extended periods of detailed observation on individual subjects is often referred to as focal-animal sampling (Altmann 1974). Such sampling is a form of nonmanipulative, observational research that has been widely used for a variety of species in captive and field settings, and allows for the incorporation of a vast array of behavioral data (Coleman and Wilson 1998; Stoinski et al. 2003; Rieucau et al. 2012; Seyfarth et al. 2012), including activity levels (Renner 1990; review in Réale et al. 2007).

Bears (family Ursidae), despite their large brain size and demonstrated cognition (Vonk et al. 2012; Benson-Amram et al. 2016; Johnson-Ulrich et al. 2016), have been largely unexamined with regard to personality (Gosling 2001; Bell et al. 2009; but see Fagen and Fagen 1996). Understanding bear behavior is critical, given that they often spatially overlap with human populations (Bateman and Fleming 2012), are known to utilize anthropogenic resources (Beckmann and Berger 2003; Hostetler et al. 2009), and can threaten human lives and property (Treves and Karanth 2003). The American black bear (Ursus americanus), for instance, is the most widely distributed North American bear, possesses many traits that allow persistence in human-dominated landscapes (Stirling and Derocher 1990; Larivière 2001; Beckmann and Berger 2003; Johnson et al. 2015), and is frequently involved in human-wildlife conflict (Can et al. 2014). Thus, elucidating bear personality may contribute to our understanding of the many ecological and evolutionary consequences of behavior, facilitate an understanding of the mechanisms inherent to the phenomenon (Wolf and Weissing 2012), and, ultimately, benefit wildlife management and conservation efforts (McDougall et al. 2006).

Here, we present the first investigation into personality of American black bears (U. americanus). Through the use of open-field, novel object, and startle object tests, and focalanimal sampling, we examine the existence of repeatable, across-context, individual differences in behavior along the bold-shy and activity axes of black bear cubs. We predicted that the bears would exhibit intra-individual consistency and inter-individual variation in behaviors across assays for each axis. Similar to previous studies (Huntingford 1976; Lantová et al. 2011; Herde and Eccard 2013), we anticipated correlation between the bold-shy and activity axes. Our study aimed to facilitate a better understanding of black bears and their behavior, include black bears in the ongoing pursuit of personality research, and broaden the tools with which we approach wildlife ecology and conservation.

\section{Methods}

Between 1 July and 29 August 2014, six orphaned black bear cubs were captured by Utah Division of Wildlife Resources personnel and transported to the US Department of Agriculture (USDA) National Wildlife Research Center's (NWRC) Predator Research Facility in Millville, Utah, USA for rehabilitation. The housing structure contained two open-air enclosures, each $16.5 \mathrm{~m}$ long, $7 \mathrm{~m}$ wide, and $2.5 \mathrm{~m}$ tall $\left(288.8 \mathrm{~m}^{3}\right)$, separated by a 7.5 -m-long, 2 -m-wide, and 2.5-m-tall transitional pen, called a "shift" (Fig. 1). The walls and ceilings of the pens and shift were chain-link fencing. Solid-metal, guillotine-style doors, operated by observers from an adjacent area, allowed for entrance and egress of bears between the pens and shift. Both pens were functionally identical and contained wooden climbing structures, logs, a large pool of water, two den boxes, natural vegetation, and a constantly flowing source of fresh water. To reduce familiarity with humans, the cubs had one primary caretaker and all bear-human interactions were minimal. All captive care was provided in accordance with the NWRC Animal Care Protocol, derived from widely accepted procedures (Beecham and Ramanathan 2007), administered NWRCSOP no. ACUT-006.00, with research permitted under the Institutional Animal Care and Use Committees at NWRC QA-2354 and a Utah State University permit (\#2434).

Bears were given at least 7 days to acclimate to various aspects of their captive environment (i.e., structures, 
Fig. 1 One of two black bear cub rehabilitation enclosures at the US Department of Agriculture National Wildlife Research Center's Predator Research Facility in Millville, Utah, USA, displaying approximate locations of object placement for two of the behavioral tests

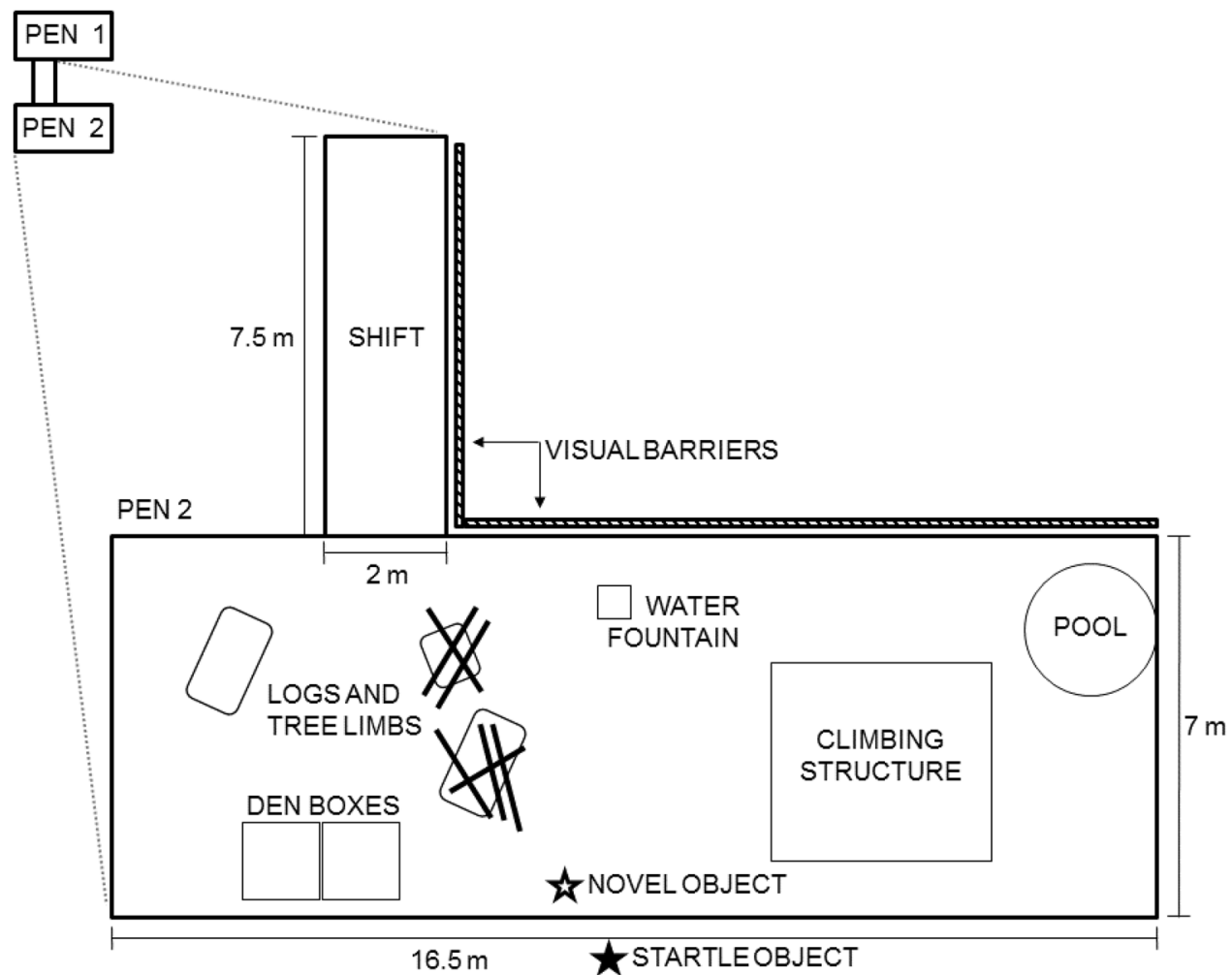

conspecifics, feeding schedule, and human caretaker) before behavioral assays began. No enrichment items were proffered to the bears during the acclimation or testing periods. Prior to the start of trials, the bears had been allowed access to one pen and the shift, but remained naïve to the second pen, which was used as the arena for several assays that would measure their responses related to the bold-shy behavioral axis. After testing that required a novel environment was completed, and the bears became familiar with both pens, we then administered bold-shy and activity tests that were not reliant on novelty of environment, with the trial pen selected opportunistically based on ease of bear isolation. Trials were ordered in a manner that preserved the novelty of individual testing paradigms; for instance, novel object trial date preceded that of the startle object, given that potential trepidation in response to introduced objects would be expected to wane with each occurrence. For all behavioral assays, we randomized dates of trials (although these were adjusted opportunistically according to weather conditions), times from all possible times during daylight hours, and subject order. As some studies have reported that olfactory or chemical cues from previous subjects or human caretakers may influence behavior (Whittier and McReynolds 1965; McCall et al. 1969), the arena and all of its contents were sprayed with high-pressure water and left to dry and ventilate for $\geq 1 \mathrm{~h}$ between all tests. All trials were conducted in mild weather between 31 August and 21 November, and administered and recorded by the same human observer.
Open-field trials were preceded by subjects being individually isolated in the shift, and all non-participating individuals confined to one pen. Following an acclimation period of 900-1800 s, we opened the door on the opposite side of the shift to allow entry into the novel pen. Prior to this point, bears did not have access to the arena, although we could not limit all arena visibility. The start of the openfield trial was delineated by the point at which the subject had entered the novel environment, defined by all four feet of the subject being on the ground of the arena. The time and duration of several coded behaviors were used to assess three measures of boldness: two variants of "wall-hugging" behavior, i.e., latency to the interior and thigmotaxis; and exploration. Latency to the interior was measured according to the number of seconds between the start of the trial and the time at which the individual entered the middle of the arena ( $>2 \mathrm{~m}$ from the perimeter), with boldness negatively related to the number of seconds. Thigmotaxis was measured as the proportion of time an individual spent at the perimeter $(<2 \mathrm{~m}$ from the fence), with the proportion inversely related to boldness. Exploration was measured as the time during which subjects actively moved about and inspected the novel environment, with boldness positively related to active behaviors. We terminated open-field trials after each subject had been in the arena for $300 \mathrm{~s}$, in order to mitigate for the animals becoming familiar with the environment. Open-field trials were recorded via four video cameras (SDR-H85; Panasonic, Osaka, Japan) placed on the exterior 
of the pen, and later analyzed using VLC software (VideoLAN, Paris).

Novel-object tests were preceded by subjects being individually isolated in the shift, and all non-participating individuals confined to the pen previously used for open-field trials. To avoid confounding subject responses to the novel object with responses associated with a stress-inducing arena, we administered novel-object tests in the familiar pen. The novel object was represented by an orange traffic cone (1 m high) placed on the floor of the arena (Fig. 1). We used a black bag to conceal the object during placement and situated the object behind a familiar solid, wooden climbing structure, until the subjects were in the arena. We recorded observations from behind visual barriers outside the arena. Following an acclimation period of 15-30 min, we opened the shift door to allow subjects access to the arena. The novel-object trial phase began when the subjects had fully entered the arena, and terminated when the subject was at $\leq 1$ - $m$ distance from the object, with the differential in time termed as latency to approach, and scores inversely related to boldness.

We conducted startle-object trials 2 days after novelobject trials. The startle object consisted of two items: a 22-cm-diameter, blue plastic ball, used to attract the interest of the test subjects; and an acoustics playback device (FOXPRO Crossfire; FOXPRO, Lewiston, PA). We situated both objects $<1 \mathrm{~m}$ outside of the arena fence, with the speaker directly behind the ball and, similar to the novel object test, obfuscated by a visual barrier until the subject had entered the arena (Fig. 1). When the subject reached the fence in front of the object, the human observer, recording behavior from behind visual barriers outside the arena, remotely activated the acoustic device. The device was programmed to emit a sound at $\sim 70 \mathrm{~dB}(\mathrm{~A})$ (at $1 \mathrm{~m}$ ), a volume loud enough to elicit a response from the test subjects, but not be heard by conspecifics in the adjacent pen. We selected an animal (raccoon Procyon lotor) growling/fighting noise as the stimulus because of its potential to produce a fear-induced response and for its novelty; unlike common testing stimuli, such as beeps, sirens, or lights, this noise would likely not have been encountered by the bears in the wild, or during capture and transport. We recorded the time between the flight response of the subjects after the sound was emitted and the subject returning to the object, with the number of seconds inversely proportional to boldness.

Focal-animal sampling occurred on days on which no other tests were administered, after all bears had been fully acclimated to both pens, and with no restrictions to pen access or conspecific interaction; these measures were to ensure that no unintended, confounding stimuli, threats, or novelty were present (Réale et al. 2007). We conducted eight focal-animal sampling events per subject, each $900 \mathrm{~s}$ in duration, with an interval average of 6 days $(\mathrm{SE}=1.3)$ between trials. The human observer recorded behaviors from behind visual barriers outside the arena. Active behaviors included locomotion, climbing, and playing alone or with conspecifics, while inactivity included sitting, lying down, or otherwise remaining stationary. We recorded time and duration of behaviors in seconds and converted these to proportions to reflect activity scores.

We conducted statistical analyses using program $\mathrm{R}$ 3.2.3 (R Development Core Team 2016). We first transformed bold-shy data for intuitive directionality, with high scores corresponding to high degrees of boldness, and rescaled data to standardize scores around a mean of 0 and a SD of 1 . Because activity scores were proportions, no rescaling or transformations were necessary. We first tested for individual consistency, or repeatability, in behavior. As described by Lessells and Boag (1987), repeatability can be characterized by the proportion of variance in responses for one individual, relative to the variance among individuals. We calculated intraclass correlation coefficients ( $R$ package irr) (Gamer et al. 2012), derived from the variance components produced by one-way ANOVA, to assess consistency of responses for each individual among the suite of tests for each of the two behavior axes. As bold-shy tests were designed to provide multiple measures for responses along the same axis, we looked for correlation between scores for each individual by performing principal component analysis (PCA). PCA reduced and enhanced directionality of variables, and illustrated relationships between variables. The number of components retained was determined according to the Kaiser-Guttman criterion (Kaiser 1991), variance contributed, and scree plot visualization. Using the loadings matrix from the retained components, composite scores were generated for each individual, representing single values for the subjects along the bold-shy continuum. Unlike bold-shy scores, activity-level scores consisted of repeated focalanimal samplings with identical measurements and units across each sampling occasion; as such, composite scores of captive activity level for each individual were achieved by averaging the eight scores. Using Spearman's rank correlation, we tested for rank-order consistency between bold-shy composite scores and activity-level composite scores.

\section{Results}

Six orphaned black bear cubs (two females, four males), approximately 8 months of age, were tested. The bears displayed intra-individual consistency and between-individual variation with regard to responses within each of the suite of tests for both the bold-shy and activity axes (Table 1). Intraclass correlation coefficients for analysis of the five bold-shy measurements indicated that some subjects were consistently more bold than others, across time and context 
Table 1 Scores from assays measuring responses of six black bear cubs for personality along the bold-shy and activity behavior axes with individual rankings ( $R ; 1$ boldest or most active, 6 least bold or active)

\begin{tabular}{|c|c|c|c|c|c|c|c|c|c|c|c|c|c|c|}
\hline Bear & Latency to interior ${ }^{\mathrm{a}}$ & $R$ & Thigmotaxis $^{\mathrm{a}}$ & $R$ & Exploration $^{\mathrm{a}}$ & $R$ & $\begin{array}{l}\text { Latency to } \\
\text { approach }^{\text {b }}\end{array}$ & $R$ & Latency to return ${ }^{\mathrm{c}}$ & $R$ & $\begin{array}{l}\text { Composite } \\
\text { bold-shy }\end{array}$ & $R$ & Activity score ${ }^{\mathrm{e}}$ & $R$ \\
\hline 1401 & -0.090 & 5 & -0.351 & 4 & 0.817 & 2 & 0.432 & 3 & -1.389 & 6 & -0.055 & 4 & 0.823 & 1 \\
\hline 1402 & -1.907 & 6 & -1.263 & 6 & -1.624 & 6 & -0.707 & 5 & -0.025 & 4 & -2.769 & 6 & 0.637 & 3 \\
\hline 1403 & 0.174 & 4 & 0.660 & 3 & -0.032 & 5 & -1.546 & 6 & 1.027 & 2 & 0.380 & 3 & 0.290 & 6 \\
\hline 1404 & 0.302 & 3 & 1.158 & 1 & 0.297 & 4 & -0.131 & 4 & 0.276 & 3 & 0.989 & 2 & 0.584 & 4 \\
\hline 1405 & 0.562 & 2 & -0.964 & 5 & 0.584 & 3 & 0.953 & 2 & -0.927 & 5 & -0.573 & 5 & 0.377 & 5 \\
\hline 1406 & 0.957 & 1 & 0.760 & 2 & 1.125 & 1 & 0.999 & 1 & 1.037 & 1 & 2.028 & 1 & 0.694 & 2 \\
\hline
\end{tabular}

${ }^{a}$ Open-field trial

${ }^{\mathrm{b}}$ Novel object trial

${ }^{\mathrm{c}}$ Startle object trial

${ }^{\mathrm{d}}$ From bold-shy assays and first PC

${ }^{\mathrm{e}}$ Mean of activity-level scores from eight focal-animal sampling trials

Table 2 Results from principal component $(P C)$ analysis of responses to captive tests of bold-shy behavior for six black bear cubs

\begin{tabular}{llc}
\hline Behavioral test & PC1 & \multicolumn{1}{l}{ PC2 } \\
\hline Latency to interior & 0.550 & -0.201 \\
Thigmotaxis & 0.529 & 0.335 \\
Exploration & 0.555 & -0.165 \\
Latency to approach & 0.204 & -0.664 \\
Startle response & 0.260 & 0.616 \\
SD & 1.627 & 1.302 \\
Proportion of variance (\%) & 52.9 & 33.9 \\
Cumulative proportion & 52.9 & 86.8 \\
\hline
\end{tabular}

The first two components were retained, explaining $87 \%$ of the overall variance. Loadings in italic represent those that contributed heavily to the formation of respective components

$\left(F_{5,20}=3.61, P=0.017\right)$. Similarly, intraclass correlation coefficients indicated that activity tests revealed some subjects to be consistently more active than others $\left(F_{5,35}=3.61\right.$, $P=0.052$ ).

PCA allowed us to retain two components, each with eigenvalues greater than 1 which, when combined, accounted for $87 \%$ of the total variance (Table 2 ). The first principal component explained $53 \%$ of the variance and was characterized by the three metrics measured in the openfield tests. PCA loadings for latency to the interior (0.550), thigmotaxis (0.529), and exploration (0.555) all contributed equally to the first principal component. Conversely, the two metrics that were associated with novel objects-latency to approach and startle object response-were the primary contributing variables for the second principle component ( -0.664 and 0.616 , respectively), which accounted for $34 \%$ of the variance.

\section{Discussion}

We present an important finding within the fields of animal behavior, ecology, and evolution - that black bears exhibit consistent individual behavioral differences. To our knowledge, this study represents the first application of testing to reveal individual personality for black bear cubs or any other species in the family Ursidae. Responses to a suite of behavioral assays commonly utilized in the field of personality research (e.g., focal-animal sampling, and open field, novel object, and startle object tests) to explore consistency of animal behavior (Bell et al. 2009) revealed that some bear cubs are consistently more bold or more active than others across contexts in captive settings. Provided that this is the first instance of such testing for bears, and considering the captive nature of bears subjected to these tests and the forms of rapid assays used (Butler et al. 2006; Biro 2012), we contend that all relevant correlations to ecological traits should be investigated further after rehabilitated bears are released into the wild.

The concept of individual variation has existed for a considerable time (Darwin 1861), and assessments of bear personality have been previously considered (Fagen and Fagen 1996). However, we are unable to compare our results to the Fagen and Fagen (1996) study, given that the authors conducted observations of brown bears (U. arctos) at a wild feeding site and considered nearly 70 subjective behavioral classifications to identify individuality among observed bears. Fagen and Fagen (1996) acknowledge several shortcomings of their study, and given that, prior to our study, this is the sole investigation into bear personality research, we highlight how this taxon has been largely overlooked.

Our study focused on black bear cubs rehabilitated in captivity until reintroduction, providing a contextual generality at a given age, time, and life experience (Stamps 
and Groothuis 2010). The personality of young animals is commonly assessed, but whether personality traits are consistent across ontogeny needs further study (Groothuis and Trillmich 2011). Because of the small sample size, and use of tests mostly conducted when individuals were isolated from the other bears, we did not control for social status in our analysis. While social structure may have existed within this cohort, we believe it would not have influenced outcomes. For instance, even in a carnivore with strong social hierarchical structure, such as the spotted hyena (Crocuta crocuta), personality dimensions were not explained by dominance status (Gosling 1998). Instead, social interactions may increase stability in individual traits used to measure personality. For example, wolf (Canis lupus) pups housed with other pups showed more stable responses to novel objects than pups housed in isolation (MacDonald 1983).

Studies of personality may prove to be a valuable tool for rehabilitated wildlife. The reasons for rehabilitation often stem from variable and nontraditional early life experiences, which are known to alter a variety of individual traits and have lasting impacts on future fitness (Lindström 1999). For instance, an individual's exposure to predators (Bell and Sih 2007) and the availability of resources (Brydges et al. 2008; Chapman et al. 2010) have been shown to influence personality. Maternal effects-one early life component that is often shortened or altered for rehabilitated wildlife-impact a variety of phenotypic expressions, with mammals being most profoundly affected, given their extended gestation, lactation, and other facets of maternal care (Reinhold 2002).

For rehabilitated bear cubs, in particular, and other animals with life histories that lend themselves to interaction with humans, personality testing could be an invaluable window to behavior after release. Administering bold-shy tests allows researchers to quantify the level of fear elicited by unfamiliar and potentially threatening objects and situations (Réale et al. 2007). Behavioral testing may be able to provide predictive insights into an individual's level of fear toward novelty. This is precisely why behavioral traits and personality have historically been referred to as "coping styles" (Koolhaas et al. 1999); reactions along the bold-shy axis may, in large part, demonstrate an organism's ability to cope with environmental conditions. Understanding an animal's boldness may reflect upon its future potential responses to anthropogenic activity and myriad other stressors after release, including its propensity to engage in conflict situations (Linnell et al. 1999).

Results of this study allude to a possible relationship between bold-shy object testing (i.e., novel and startle) and captive activity level. Previous studies have reported relationships between boldness and activity axes (Boyer et al. 2010; Lantová et al. 2011; Dammhahn 2012; Herde and Eccard 2013), while others have demonstrated links between those traits and dispersal (Fraser et al. 2001; Dingemanse et al. 2003) or space use (Boon et al. 2007; Minderman et al. 2010). Although we did not relate tests to behavior of bears after release, we believe our study provides a framework for future rehabilitation and release programs interested in assessing individual behavior and correlates to post-release behavior and space use.

While behavioral phenotype may shift later in life due to internal changes or environmental stressors (Stamps and Groothuis 2010), the expressions exhibited by rehabilitated wildlife during personality assays shortly before release may mean the difference between life and death in a species with potentially lethal conspecific interactions (Sih and Bell 2008), or in a world of immediate anthropogenic dangers (Wilcove et al. 1998). Previous research has identified correlations between personality and the fitness and behavior of animals after reintroduction (Cavigelli and McClintock 2003; Bremner-Harrison et al. 2004; Smith and Blumstein 2008). Identifying the mechanisms that shape and are shaped by behavioral traits is fundamental to understanding individual life history and population dynamics (Stamps and Groothuis 2010).

Ultimately, understanding the mechanisms behind animal behavior and broadening our scope to include new species in personality research will illuminate relationships to fundamental components of life history and species ecology. Through this, we hope to facilitate a better understanding of black bears and their behavior, include black bears in the ongoing pursuit of personality research, and broaden the tools with which we approach wildlife ecology, management, and conservation.

Acknowledgements We wish to thank the Utah Division of Wildlife Resources for allowing us to conduct this study and for their technical support. We thank S. Brummer, E. Stevenson, J. Schultz, N. Floyd, and M. Davis at the USDA NWRC Predator Research Facility for their assistance. Earlier drafts of this manuscript were reviewed by F. Howe, K. Jordan, and two anonymous reviewers. Funding was provided by the Utah Division of Wildlife Resources, the Department of Wildland Resources at Utah State University, and the USDA National Wildlife Resource Center. Any use of trade, firm, or product names is for descriptive purposes only and does not imply endorsement by the U.S. Government.

\section{Compliance with ethical standards}

Conflict of interest The authors declare that they have no conflict of interest.

Human and animal rights statement All applicable international, national, and/or institutional guidelines for the care and use of animals were followed. Captive care and handling was administered through NWRC-SOP no. ACUT-006.00, with research permitted under NWRC Institutional Animal Care and Use Committee (IACUC) permit QA-2354 and Utah State University IACUC permit \#2434. This article does not contain any studies with human participants performed by any of the authors. 


\section{References}

Adriaenssens B, Johnsson JI (2010) Shy trout grow faster: exploring links between personality and fitness-related traits in the wild. Behav Ecol 22(1):135-143

Altmann J (1974) Observational study of behavior: sampling methods. Behaviour 49(3):227-266

Bateman PW, Fleming PA (2012) Big city life: carnivores in urban environments. J Zool 287(1):1-23

Beckmann JP, Berger J (2003) Rapid ecological and behavioural changes in carnivores: the responses of black bears (Ursus americanus) to altered food. J Zool 261(2):207-212

Beecham JJ, Ramanathan A (2007) Proceedings, 2007 International Workshop on the Rehabilitation Release and Monitoring of Orphan Bear Cubs. Bubonitsy, Russia, pp 23-31

Bell AM, Sih A (2007) Exposure to predation generates personality in three spined sticklebacks (Gasterosteus aculeatus). Ecol Lett 10(9):828-834

Bell AM, Hankison SJ, Laskowski KL (2009) The repeatability of behaviour: a meta-analysis. Anim Behav 77(4):771-783

Benson-Amram S, Dantzer B, Stricker G, Swanson EM, Holekamp KE (2016) Brain size predicts problem-solving ability in mammalian carnivores. Proc Natl Acad Sci USA 113(9):2532-2537

Biro PA (2012) Do rapid assays predict repeatability in labile (behavioural) traits? Anim Behav 83(5):1295-1300

Boon AK, Réale D, Boutin S (2007) The interaction between personality, offspring fitness and food abundance in North American red squirrels. Ecol Lett 10(11):1094-1104

Boyer N, Réale D, Marmet J, Pisanu B, Chapuis JL (2010) Personality, space use and tick load in an introduced population of Siberian chipmunks Tamias sibiricus. J Anim Ecol 79(3):538-547

Bremner-Harrison S, Prodohl PA, Elwood RW (2004) Behavioural trait assessment as a release criterion: boldness predicts early death in a reintroduction programme of captive-bred swift fox (Vulpes velox). Anim Conserv 7(03):313-320

Brydges NM, Colegrave N, Heathcote RJ, Braithwaite VA (2008) Habitat stability and predation pressure affect temperament behaviours in populations of three-spined sticklebacks. J Anim Ecol 77(2):229-235

Burns JG (2008) The validity of three tests of temperament in guppies (Poecilia reticulata). J Comp Psychol 122(4):344-356

Butler SJ, Whittingham MJ, Quinn JL, Cresswell W (2006) Time in captivity, individual differences and foraging behaviour in wildcaught chaffinches. Behaviour 143(4):535-548

Can ÖE, D'Cruze N, Garshelis DL, Beecham J, Macdonald DW (2014) Resolving human-bear conflict: a global survey of countries, experts, and key factors. Conserv Lett 7(6):501-513

Careau V, Thomas D, Humphries MM, Réale D (2008) Energy metabolism and animal personality. Oikos 117(5):641-653

Caspi A, Roberts BW, Shiner RL (2005) Personality development: stability and change. Annu Rev Psychol 56:453-484

Cavigelli SA, McClintock MK (2003) Fear of novelty in infant rats predicts adult corticosterone dynamics and an early death. Proc Natl Acad Sci USA 100(26):16131-16136

Chapman BB, Morrell LJ, Krause J (2010) Unpredictability in food supply during early life influences boldness in fish. Behav Ecol 21(3):501-506

Cole EF, Quinn JL (2014) Shy birds play it safe: personality in captivity predicts risk responsiveness during reproduction in the wild. Biol Lett 10(5):20140178

Coleman K, Wilson DS (1998) Shyness and boldness in pumpkinseed sunfish: individual differences are context-specific. Anim Behav 56(4):927-936

Cote J, Clobert J (2007) Social personalities influence natal dispersal in a lizard. Proc R Soc Lond B Biol 274(1608):383-390
Cote J, Clobert J, Brodin T, Fogarty S, Sih A (2010) Personalitydependent dispersal: characterization, ontogeny and consequences for spatially structured populations. Proc R Soc Lond B Biol 365(1560):4065-4076

Dammhahn M (2012) Are personality differences in a small iteroparous mammal maintained by a life-history trade-off? Proc $\mathrm{R}$ Soc Lond B Biol (published online). https://doi.org/10.1098/ rspb.2012.0212)

Darwin C (1861) On the origin of species, 3rd edn. Murray, London

Dingemanse NJ, Réale D (2005) Natural selection and animal personality. Behaviour 142(9-10):1159-1184

Dingemanse NJ, Both C, Van Noordwijk AJ, Rutten AL, Drent PJ (2003) Natal dispersal and personalities in great tits (Parus major). Proc R Soc Lond B Biol 270(1516):741-747

Dingemanse NJ, Kazem AJ, Réale D, Wright J (2010) Behavioural reaction norms: animal personality meets individual plasticity. Trend Ecol Evol 25(2):81-89

Fagen R, Fagen JM (1996) Individual distinctiveness in brown bears, Ursus arctos L. Ethology 102(2):212-226

Fraser DF, Gilliam JF, Daley MJ, Le AN, Skalski GT (2001) Explaining leptokurtic movement distributions: intrapopulation variation in boldness and exploration. Am Nat 158(2):124-135

Gamer M, Lemon J, Fellows I, Singh P (2012) irr: various coefficients of interrater reliability and agreement. $\mathrm{R}$ package version 0.84

Gosling SD (1998) Personality dimensions in spotted hyenas (Crocuta crocuta). J Comp Psychol 112(2):107-118

Gosling SD (2001) From mice to men: what can we learn about personality from animal research? Psychol Bull 127(1):45-86

Groothuis TG, Trillmich F (2011) Unfolding personalities: the importance of studying ontogeny. Dev Psychobiol 53(6):641-655

Herde A, Eccard JA (2013) Consistency in boldness, activity and exploration at different stages of life. BMC Ecol 13(1):49

Hostetler JA, McCown JW, Garrison EP, Neils AM, Barrett MA, Sunquist ME, Simek SL, Oli MK (2009) Demographic consequences of anthropogenic influences: Florida black bears in north-central Florida. Biol Conserv 142(11):2456-2463

Huntingford FA (1976) The relationship between anti-predator behaviour and aggression among conspecifics in the three-spined stickleback, Gasterosteus aculeatus. Anim Behav 24(2):245-260

Johnson JC, Sih A (2005) Precopulatory sexual cannibalism in fishing spiders (Dolomedes triton): a role for behavioral syndromes. Behav Ecol Sociobiol 58(4):390-396

Johnson HE, Breck SW, Baruch-Mordo S, Lewis DL, Lackey CW, Wilson KR, Broderick J, Mao JS, Beckmann JP (2015) Shifting perceptions of risk and reward: dynamic selection for human development by black bears in the western United States. Biol Conserv 187:164-172

Johnson-Ulrich Z, Vonk J, Humbyrd M, Crowley M, Wojtkowski E, Yates F, Allard S (2016) Picture object recognition in an American black bear (Ursus americanus). Anim Cogn 19(6):1237-1242

Kaiser HF (1991) Coefficient alpha for a principal component and the Kaiser-Guttman rule. Psychol Rep 68:855-858

Kallai J, Makany T, Csatho A, Karadi K, Horvath D, Kovacs-Labadi B, Jarai R, Nadel L, Jacobs JW (2007) Cognitive and affective aspects of thigmotaxis strategy in humans. Behav Neurosci 121(1):21-30

Koolhaas JM, Korte SM, De Boer SF, Van Der Vegt BJ, Van Reenen CG, Hopster H, De Jong IC, Ruis MAW, Blokhuis HJ (1999) Coping styles in animals: current status in behavior and stressphysiology. Neurosci Biobehav Rev 23(7):925-935

Kortet R, Hedrick ANN (2007) A behavioural syndrome in the field cricket Gryllus integer: intrasexual aggression is correlated with activity in a novel environment. Biol J Linn Soc 91(3):475-482 
Lantová P, Šíchová K, Sedláček F, Lanta V (2011) Determining behavioural syndromes in voles-the effects of social environment. Ethology 117(2):124-132

Larivière S (2001) Ursus americanus. Mamm Species 647:1-11

Lessells CM, Boag PT (1987) Unrepeatable repeatabilities: a common mistake. Auk 104:116-121

Lindström J (1999) Early development and fitness in birds and mammals. Trends Ecol Evol 14(9):343-348

Linnell JD, Odden J, Smith ME, Aanes R, Swenson JE (1999) Large carnivores that kill livestock: do "problem individuals" really exist? Wildl Soc Bull 27(3):698-705

MacDonald K (1983) Stability of individual differences in behavior in a litter of wolf cubs (Canis lupus). J Comp Psychol 97(2):99-106

McCall RB, Lester ML, Corter CM (1969) Caretaker effect in rats. Dev Psychol 1(6):750-762

McDougall PT, Réale D, Sol D, Reader SM (2006) Wildlife conservation and animal temperament: causes and consequences of evolutionary change for captive, reintroduced, and wild populations. Anim Conserv 9(1):39-48

Meehan CL, Mench JA (2002) Environmental enrichment affects the fear and exploratory responses to novelty of young Amazon parrots. Appl Anim Behav Sci 79(1):75-88

Mettke-Hofmann C, Winkler H, Leisler B (2002) The significance of ecological factors for exploration and neophobia in parrots. Ethology 108(3):249-272

Minderman J, Reid JM, Hughes M, Denny MJ, Hogg S, Evans PG, Whittingham MJ (2010) Novel environment exploration and home range size in starlings Sturnus vulgaris. Behav Ecol 21(6):1321-1329

R Development Core Team (2016) R: a language and environment for statistical computing. R Foundation for Statistical Computing, Vienna. http://www.R-project.org. Accessed Oct 2017

Réale D, Reader SM, Sol D, McDougall PT, Dingemanse NJ (2007) Integrating animal temperament within ecology and evolution. Biol Rev 82(2):291-318

Réale D, Martin J, Coltman DW, Poissant J, Festa-Bianchet M (2009) Male personality, life-history strategies and reproductive success in a promiscuous mammal. J Evol Biol 22(8):1599-1607

Réale D, Dingemanse NJ, Kazem AJ, Wright J (2010) Evolutionary and ecological approaches to the study of personality. Philos Trans R Soc B 365(1560):3937-3946

Reinhold K (2002) Maternal effects and the evolution of behavioral and morphological characters: a literature review indicates the importance of extended maternal care. J Hered 93(6):400-405

Renner MJ (1990) Neglected aspects of exploratory and investigatory behavior. Psychobiology 18(1):16-22

Rieucau G, Blanchard P, Martin JG, Favreau FR, Goldizen AW, Pays $\mathrm{O}$ (2012) Investigating differences in vigilance tactic use within and between the sexes in eastern grey kangaroos. PLoS One 7(9):e44801
Seyfarth RM, Silk JB, Cheney DL (2012) Variation in personality and fitness in wild female baboons. Proc Natl Acad Sci USA 109(42):16980-16985

Sharma S, Coombs S, Patton P, de Perera TB (2009) The function of wall-following behaviors in the Mexican blind cavefish and a sighted relative, the Mexican tetra (Astyanax). J Comp Physiol A 195(3):225-240

Sih A, Bell AM (2008) Insights for behavioral ecology from behavioral syndromes. Adv Study Behav 38:227-281

Sih A, Bell A, Johnson JC (2004) Behavioral syndromes: an ecological and evolutionary overview. Trends Ecol Evol 19(7):372-378

Smith BR, Blumstein DT (2008) Fitness consequences of personality: a meta-analysis. Behav Ecol 19(2):448-455

Stamps J, Groothuis TG (2010) The development of animal personality: relevance, concepts and perspectives. Biol Rev 85(2):301-325

Stirling I, Derocher AE (1990) Factors affecting the evolution and behavioral ecology of the modern bears. Int C Bear 8:189-204

Stoinski TS, Beck BB, Bloomsmith MA, Maple TL (2003) A behavioral comparison of captive-born, reintroduced golden lion tamarins and their wild-born offspring. Behaviour 140(2):137-160

Treit D, Fundytus M (1988) Thigmotaxis as a test for anxiolytic activity in rats. Pharmacol Biochem Behav 31(4):959-962

Treves A, Karanth KU (2003) Human-carnivore conflict and perspectives on carnivore management worldwide. Conserv Biol 17(6):1491-1499

Valle FP (1970) Effects of strain, sex, and illumination on open-field behavior of rats. Am J Psychol 83(1):103-111

Van Oers K, Drent PJ, De Goede P, Van Noordwijk AJ (2004) Realized heritability and repeatability of risk-taking behaviour in relation to avian personalities. Proc R Soc Lond B Biol 271(1534):65-73

Vonk J, Jett SE, Mosteller KW (2012) Concept formation in American black bears, Ursus americanus. Anim Behav 84(4):953-964

Walsh RN, Cummins RA (1976) The open-field test: a critical review. Psychol Bull 83(3):482-504

Ward AJ, Webster MM, Hart PJ (2007) Social recognition in wild fish populations. Proc Soc Lond B Biol 274(1613):1071-1077

West-Eberhard MJ (1989) Phenotypic plasticity and the origins of diversity. Annu Rev Ecol Syst 20:249-278

Whittier JL, McReynolds P (1965) Persisting odors as a biasing factor in open-field research with mice. Can J Psychol 19(3):224-230

Wilcove DS, Rothstein D, Dubow J, Phillips A, Losos E (1998) Quantifying threats to imperiled species in the United States. Bioscience 48(8):607-615

Wilson DS, Clark AB, Coleman K, Dearstyne T (1994) Shyness and boldness in humans and other animals. Trends Ecol Evol 9(11):442-446

Wolf M, Weissing FJ (2012) Animal personalities: consequences for ecology and evolution. Trends Ecol Evol 27(8):452-461 